\title{
Negatividade e inversão da Dialética Especulativa de Hegel - notas sobre o desenvolvimento teórico de Karl Marx
}

Andre de Góes Cressoni

Resumo: Nas tentativas de elaborar uma análise quanto ao desenvolvimento teórico do jovem Marx até suas teses de maturidade, há uma dicotomia rompimento/continuidade que, por sua predominância, tem a tendência de enfraquecer as interpretações marxianas. Nesta problemática, o presente artigo busca analisar, sucintamente, o desenvolvimento teórico de Marx como uma unidade de rompimento e continuidade. Para tanto, é necessário remeter-se ao legado hegeliano, sem o qual a dialética de Marx perde a linha que unifica e ao mesmo tempo separa essas duas fases de seu pensamento. Tendo como referências principais os "Manuscritos Econômico-Filosóficos", a "Ideologia Alemã ", e "O Capital", defendemos que o ponto nodal deste debate consiste na relação entre o caráter especulativo da dialética hegeliana e o conceito de negatividade tal como aparece no decorrer da obra de Marx, adquirindo, a partir disso, uma reinterpretação da palavra umstülpen (inversão) para compreender no que consiste a inversão que Marx opera na dialética hegeliana.

Palavras-chave: Marx, Hegel, Dialética.

Abstract: In the attempts to elaborate an analysis on the theoretical development from the young Marx to his maturity thesis there is a rupture/continuity dicotomy, which by its predominance has the tendency to weaken these interpretations. In this matter, this present paper seeks to briefly analyse Marx's theoretical development as a unity of rupture and continuity. For this, it is necessary to refer to the Hegelian legacy without which Marx's dialectics loses the line that unifies and at the same time separates these two phases of his thought.

* Doutorando no curso de filosofia da UNICAMP. 
Having as the main references the Economic-Philosophical Manuscripts, the German Ideology and Capital, we defend that the nodal point of this debate lies on the relation between the specultive character of the Hegelian dialectics and the concept of negativity as it appears on the elapse of Marx's work, and by this aquiring a re-interpretation of the word umstülpen (inversion) to comprehend in what consists the inversion Marx operates on the Hegelian dialectics.

Keywords: Marx, Hegel, Dialectics.

\section{Introdução}

A dialética de Marx, ainda que muito debatida, está carregada ainda de enigmas quanto à sua relação com a dialética especulativa de Hegel. A visão que se tentará elaborar consiste em analisar como esta relação com Hegel ilumina um dos pontos centrais para a compreensão do desenvolvimento teórico que perpassa a obra de Marx, desde seus Manuscritos Econômico-Filosóficos de 1844, até, enfim, O Capital.

Ao contrário de algumas leituras correntes, não se trata de encontrar uma continuidade ou ruptura absoluta entre as teses do dito jovem Marx e suas teses de maturidade. O que se tentará, ao contrário, é encontrar uma problemática que sirva de fio condutor e que perpasse seu pensamento: não uma tese positiva, mas uma tentativa contínua de resolução de um princípio - o princípio da dialética - que faz convergir outras questões derivadas do posicionamento deste princípio, e que Marx parece nunca ter abandonado.

Tendo em vista que uma empreitada deste calibre consistiria em análises de uma vasta amplitude, trataremos de investigar, em termos gerais, como certas concepções em Marx atravessam e se transformam no decorrer de sua obra, e como estas deixam transparecer uma problemática que somente em $O$ Capital o autor teria conseguido resolver.

100 Negatividade e inversão da Dialética Especulativa de Hegel... 


\section{A dialética do trabalho e o ser genérico nos Manuscritos Econômico-Filosóficos de 1844}

Na obra intitulada Manuscritos Econômico-Filosóficos, Marx elabora o que seria sua compreensão materialista da história, assim como seu enfrentamento direto com a dialética de Hegel. Esta empreitada consiste, sobretudo, em desvelar o fundamento concreto do real a partir de uma crítica do idealismo hegeliano que se enraizou entre os intelectuais alemães de esquerda. Dentre eles, Marx tinha por maior estima Feuerbach: "Feuerbach é o único que tem para com a dialética hegeliana um comportamento sério, crítico" (MARX, 2004, p. 117). E acrescenta que este teria realizado a "fundação do verdadeiro materialismo e da ciência real", já que toma "a relação social, a 'do homem com o homem', como princípio fundamental da teoria” (Ibid., p. 118).

É nesse sentido que Marx partirá para a teorização da dialética do trabalho. O trabalho seria um ponto de mediação entre homem e sociedade, e sociedade e natureza. Marx trata, aqui, do "gênero humano", e empreende uma análise daquilo que ele chamaria de "essência" do homem. Segundo esta tese, o gênero e a natureza convergiriam, a natureza como o corpo inorgânico do gênero. Porém, o trabalho seria essa força mediadora que leva o mesmo a se realizar concretamente. Através de uma exteriorização do gênero na natureza e uma interiorização da natureza no gênero, o trabalho seria este motor que faz mover a espécie como um todo.

Decorre disto que, por um lado, a mediação do trabalho tem como resultado a universalização das relações humanas para com a natureza, ao aprimorar o próprio trabalho e a criação de novas necessidades; por outro lado, entretanto, a própria concretização dessa universalidade só seria possível na medida em que o aprimoramento do trabalho e a criação de novas necessidades fossem realizadas não individualmente, mas tendo por fundamento o gênero. A mediação do trabalho coincide com a mediação da espécie, como fundamentos da vida humana: 
"A vida produtiva é, porém, a vida genérica (...). No modo (Art) da atividade vital encontra-se o caráter inteiro de uma species, seu caráter genérico" (Ibid, p. 84). A relação natural e concreta, fundamento materialista do homem, é a própria relação social concretizada, uma não se separando da outra.

“Precisamente por isso, na elaboração do mundo objetivo [é que] o homem se confirma, em primeiro lugar e efetivamente, como ser genérico. Esta produção é a sua vida genérica operativa" (Ibid., p. 85).

Seguindo a herança de Feuerbach, Marx confere a toda manifestação do indivíduo o caráter, direta ou indiretamente, da universalidade da espécie. As experiências pessoais de cada indivíduo dizem respeito a um mundo não somente objetivo, mas pressupondo uma intersubjetividade que se realiza na qualidade de objetividade da espécie humana. Esta objetividade se dá mediante cada indivíduo que representa, na sua própria singularidade, o gênero humano. Ambas se convertem mutuamente:

“O homem é um ser genérico (Gattungswesen), não somente quando prática e teoricamente faz do gênero (...) o seu objeto, mas também (...) quando se relaciona consigo mesmo como [com] o gênero vivo, presente, quando se relaciona consigo mesmo como [com] um ser universal, [e] por isso livre" (Ibid., p. 84).

A universalidade da espécieé, portanto, formadapordoisaspectos que coincidem: o trabalho e o indivíduo. A determinação universal compreende todas as particularidades que se consubstancializam no gênero. Em outras palavras, se em toda atividade o indivíduo efetiva a espécie, uma vez que é ele o ser social, esta efetivação, por sua vez, só pode se realizar concretamente na medida em que no indivíduo

102 Negatividade e inversão da Dialética Especulativa de Hegel... 
se encarnam as forças genéricas capazes de exteriorizar a espécie na natureza e interiorizar a natureza na espécie. Portanto, o gênero é o caráter universal e concreto, fundamento, de cada atividade individual humana, e o indivíduo é o átomo dinâmico que dá movimento a este corpo social.

É necessário, entretanto, analisarmos as consequências destas afirmações. Em primeiro lugar, Marx não é, nesta época, ignorante da contradição entre capital e trabalho ${ }^{1}$. No entanto, apesar de levantar a tese sobre a contradição entre capital e trabalho, a conexão entre esta e as teses da alienação do trabalho, do produto do trabalho, sobre a propriedade privada e da consciência genérica, permanecem soltas, sem apresentar ainda uma unidade teórica rigorosa entre elas. Entretanto, veja-se que Marx, nesta época, tem como tese principal a dialética do trabalho. Esta tese, por sua vez, coloca o indivíduo, todas as relações sociais e até mesmo a alienação, sob o fundamento do ser genérico (Gattungswesen). Toda a dialética do trabalho está estruturada sobre este solo comum:
"A essência humana da natureza está, em primeiro lugar, para o homem social; pois é primeiro aqui que ela existe para ele na condição de elo com o homem, na condição de existência sua para o outro e do outro para ele; é primeiro aqui que ela existe como fundamento da sua própria existência humana" (Ibid., p. 106-107).

Sustentando uma tese materialista do ser genérico, Marx tem a intenção de destruir o elemento idealista de Hegel: “O Si é, porém,

\footnotetext{
${ }^{1}$ Contra as posições defendidas aqui, poderia se objetar que as reflexões de Marx quanto à contradição capital-trabalho constituiria o ponto de continuidade de sua obra. Entretanto, apesar de haver alguns pontos levantados em sua juventude que Marx não deixará de incorrer até sua maturidade, acreditamos que estes sofrem mudanças consideráveis que só podem ser compreendidas diante da reformulação da dialética, como será defendida no prosseguimento deste artigo.
} 
somente o homem abstratamente concebido e gerado por meio da abstração" (Ibid., p. 125). Deste modo, Marx acreditou, seguindo Feuerbach, estabelecer a crítica mais contundente da dialética idealista de Hegel$^{2}$.

Mas bastaria operar uma mera inversão das categorias? Bastaria meramente colocar um fundamento materialista para os conceitos abstratos que Hegel havia estabelecido? Vejamos melhor.

Com a tese da dialética do trabalho, Marx elaborava a crítica materialista dos pressupostos abstratos de Hegel que o levaria, em "A sagrada família" e em "A Ideologia Alemã", a travar uma verdadeira batalha contra os hegelianos ditos de esquerda na Alemanha. Porém, a dialética do trabalho tinha por fundamento último a unidade do ser genérico como essência humana. Apesar de apontar as deficiências idealistas, com a tese do ser genérico como unidade que fundamenta todas as contradições do real, Marx não teria conseguido ultrapassar o caráter especulativo do pensamento hegeliano. Na filosofia hegeliana a Ideia constitui a unidade última do Espírito. Deste modo, Hegel tem em mãos o eixo que culmina na sistemática de sua filosofia: se o pensamento é uno consigo mesmo, pode perpetrar-se a unidade fundamental do Espírito mesmo diante de todas as contradições do real.

\begin{abstract}
"Desse modo, o espírito vem a si mesmo, no mais profundo sentido da palavra, porque seu princípio (...) é o pensar. Mas nesse empreendimento acontece que o pensar se enreda em contradições; isto é, perde-se na rígida não-identidade dos pensamentos: por isso não atinge a si mesmo, [mas] antes fica preso em seu contrário. A necessidade [Bedürfnis] superior vai contra esse resultado do pensar [que é] apenas o entendimento,
\end{abstract}

\footnotetext{
${ }^{2}$ É interessante notar, porém, como Marx se utiliza do conceito de trabalho hegeliano para superar algumas teses de Feuerbach sobre o materialismo, principalmente no que tange à possibilidade lógica de uma história, colocando, assim, ao contrário de Feuerbach, novas bases para uma tese materialista com a dialética do trabalho.
}

104 Negatividade e inversão da Dialética Especulativa de Hegel... 
e está baseada em que o pensar não se abandona: fica fiel a si mesmo nessa sua perda consciente de seu ser-junto-a-si [Beisichseins]. "para que ele vença", [e] leve a termo no pensar mesmo a resolução de suas próprias contradições" (HEGEL, 1995, p. 51).

O sistema especulativo consiste em mostrar que as contradições são resolvidas, em última instância, na unidade da razão como a verdade do real. É por isso que toda a história não passaria senão de um processo de autoconhecimento de si e por si mesmo do Espírito. Afirma Hegel na Fenomenologia do Espírito:

“O que no espírito nela se prepara é o elemento do saber. Agora se expandem nesse elemento os momentos do espírito na forma da simplicidade, que sabe seu objeto como a si mesma. Esses momentos já não incidem na oposição entre o ser e o saber, separadamente; mas ficam na simplicidade do saber - são o verdadeiro na forma do verdadeiro, e sua diversidade é só diversidade de conteúdo. Seu movimento, que nesse elemento se organiza em um todo, é a Lógica ou Filosofia Especulativa" (HEGEL, 2005, p. 47).

A "forma da simplicidade", a unidade simples do Espírito consigo mesmo, que se diferencia no seu conteúdo, mas que não abandona a unidade lógica, é o que "nesse elemento se organiza em um todo". É necessário atentar para a diferenciação que há em Hegel entre o Conceito e a Ideia. De um lado, o Conceito consiste na lógica do próprio real, em-si racional, e, de outro lado, a Ideia consiste no reconhecimento desta unidade do pensar com aquela do objeto pelo Espírito, e por isso é para-si: atinge-se, portanto, a unidade do em-sipara-si, o real que é a razão reconhece-se em si mesmo como razão, e por isso é a Ideia Absoluta. 
Hegel se utiliza de dois termos que servem de tradução para 'necessidade': Notwendigkeit e Bedürfnis ${ }^{3}$. Ambos expressam a necessidade lógica do percurso dialético. Assim, a necessidade (Notwendigkeit) do Conceito, da lógica objetiva do mundo, se realiza de maneira a revelar a necessidade (Bedürfnis) da Ideia em reconhecer na lógica do mundo a unidade do pensar a si mesmo do Espírito, resolvendo, derradeiramente, as contradições. Assim alude Hegel, ao criticar a maneira do entendimento de fazer ciência, rebatendo-a com o modo verdadeiramente científico, isto é, o dialético-especulativo.

\begin{abstract}
“Na maneira, acima aludida, de [fazer] ciência, por um lado o universal que nele está contido - o gênero etc. -, enquanto por si indeterminado, não está, por si, ligado ao particular; mas ambos são um para o outro exteriores e contingentes; como também as particularidades unidas são, para si, reciprocamente, exteriores e contingentes (...) Nos dois [casos] não se dá satisfação à forma da necessidade ( Notwendigkeit). O refletir, na medida em que visa a proporcionar a satisfação a esta necessidade (Bedürfnis) é o pensamento propriamente filosófico, o pensamento especulativo" (HEGEL, 1995, p. 49).
\end{abstract}

Vê-se como Hegel postula a unidade entre a necessidade interna ao objeto e a necessidade do próprio pensar, reconhecendo no objeto seu elemento comum: a razão.

Ora, as teses de Marx nos Manuscritos de 1844 não diferem a ponto de colocar em xeque a forma lógica deste elemento especulativo. Afirma Marx:

${ }^{3}$ Bedürfnis pode ser entendido como 'carecimento', que apontaria, no caso hegeliano, para o carecer do Espírito de reconhecer-se como razão da história, sintetizando na consciência-de-si a unidade com a necessidade (Notwendigkeit) do desenvolvimento lógico do real.

106 Negatividade e inversão da Dialética Especulativa de Hegel... 
O homem, no qual a sua efetivação própria existe como necessidade (Notwendigkeit) interior, como falta (Not). (...) Ela é o elo passivo que deixa sentir ao homem a maior riqueza, o outro homem como necessidade (Bedürfnis) (MARX, 2004, p. 113).

O que vemos se desenrolar na tese da dialética do trabalho de Marx consiste em que o autor reconstrói a unidadelógica especulativa da dialética hegeliana, pois coloca a necessidade (Bedürfnis) de reconhecer no outro homem uma necessidade (Notwendigkeit) interna ao próprio gênero. Retoma-se, assim, no interior do próprio materialismo, aquela especulatividade hegeliana onde todas as contradições do real se resolvem.

Deste modo, Marx teria criticado o caráter idealista de Hegel ao postular a realidade in abstracto. Porém, retoma a forma lógica do elemento especulativo hegeliano para dar fundamento à dialética do trabalho. Em Hegel, porém, não há divergência entre o caráter idealista e especulativo. O que importa para nós, entretanto, é que todas as figuras do Espírito em suas contradições se resolvem nesta unidade ontológica do Espírito consigo mesmo. É neste sentido que, apesar de não buscar uma realidade somente no âmbito do pensamento, Marx postula que todas as contradições do real se resolvem na unidade ontológica do ser genérico.

\section{Novos horizontes para o Materialismo Histórico: os anos de 1845 a 1848}

No ano seguinte, 1845, Marx elabora uma obra em conjunto com Engels, A Ideologia Alemã. Ali suas teses parecem ganhar outro tom:

É então também natural que todas as relações dos homens podem ser deduzidas do conceito de homem, do homem representado, 
da essência do homem, do homem. Assim procedeu a filosofia especulativa (MARX, 1987, p. 76) ${ }^{4}$.

Apesar de haver em grande parte reflexões que são o eco das ideias presentes nos Manuscritos de 1844, veja-se como o autor aponta, aqui, uma crítica quanto à representação do homem como essência. Em outras passagens Marx insiste nesta crítica.

Esta soma de forças de produção, de capitais, de formas sociais de intercâmbio, que cada indivíduo e cada geração encontram como algo dado, é o fundamento real daquilo que os filósofos representaram como 'substância' e 'essência do homem' (Ibid., p. 56).

Estes apontamentos se inserem no contexto de uma tese que já está sendo deixada para trás. Marx colocara a "essência do homem" como fundamento de toda dialética do trabalho. Deste modo, a história consistia no processo de autoformação do gênero, conservando as características lógicas do Espírito hegeliano. Suas novas indagações, porém, ao que tudo indica, constitui uma problemática única que está em desenvolvimento: a forma da dialética. Assim, Marx não aceita mais as teses de Feuerbach, e contrapõe à tese sobre "o homem" a nova tese dos "homens históricos reais":

A "concepção" feuerbachiana do mundo sensível limita-se, de um lado, à simples contemplação deste último e, de outro lado, ao simples sentimento; ele diz "o homem" ao invés de dizer os "homens históricos reais" (Ibid., p. 66).

\footnotetext{
${ }^{4}$ É importante deixar claro que a crítica a Hegel sempre se deu através do uso dos termos 'idealistas' e 'especulativos' desde os "Manuscritos" de 1844 quando se atacava as teses de Hegel, não ocorrendo mudança, neste sentido, entre este em A Ideologia Alemã.
} 
E insiste mais adiante:

Se considerarmos filosoficamente este desenvolvimento dos indivíduos nas condições comuns de existência dos estamentos e das classes, que se sucedem historicamente, e nas representações gerais que lhe foram impostas, é certamente muito fácil imaginar que nestes indivíduos desenvolveu-se o gênero ou o homem, ou que eles desenvolveram o homem - uma imaginação através da qual são dados alguns fortes bofetões na história (Ibid., p. 118).

Marx, portanto, não parece mais satisfeito com uma tese pautada na mera inversão das categorias hegelianas. Sugere-se um novo horizonte, ainda não muito definido, mas que seria a continuidade quanto à forma dialética que as teses de 1844 haviam deixado insatisfeita. Aponta Marx, criticando os hegelianos de esquerda, como Bruno Bauer, Max Stirner e mesmo Feuerbach:

Inicialmente, tomam-se categorias hegelianas puras, isentas de falsificação, tais como as de substância e autoconsciência; depois, profanam-se as categorias com nomes mais mundanos, tais como os de Gênero, Único, o Homem, etc. (Ibid., p. 24).

Veja-se como Marx parece indicar as próprias categorias de que se utilizou há pouco tempo antes de escrever estas linhas. Estaria Marx revirando suas próprias concepções, e planejando uma destruição daquelas categorias que consistiam meramente numa profanação da dialética hegeliana? De fato, assim parece indicar o texto. E ainda, afirma Marx, no Prefácio em Para a Crítica da Economia Política, ao tratar do manuscrito de A Ideologia Alemã: 
O manuscrito (...) já havia chegado há muito tempo à editoria em Westfália quando formos informados de que a impressão fora impedida por circunstâncias adversas. Abandonamos o manuscrito à crítica roedora dos ratos, tanto mais a gosto quando já havíamos atingido o fim principal: a compreensão de si mesmo (MARX, 1978, p. 131).

Retrata que, ao encontrar-se com Engels em Bruxelas, no exílio, dirigiram-se a "elaborar em comum nossa oposição contra o que há de ideológico na filosofia alemã", e acrescenta sintomaticamente que "tratava-se, de fato, de acertar as contas com a nossa antiga consciência filosófica" (Ibid., p. 130-131). Ao mesmo tempo, assume Marx que quando ainda era redator da Gazeta Renana, tendo de lidar com as filosofias francesas sobre o socialismo e comunismo, "confessei francamente que os meus estudos feitos até então não me permitiam ousar qualquer julgamento sobre o conteúdo das correntes francesas", e que "O primeiro trabalho que empreendi para resolver a dúvida que me assediava foi uma revisão crítica da filosofia do direito de Hegel", resultando na Introdução à Crítica da Filosofia do Direito de Hegel.

É nesta época, em 1845, que Marx é expulso da França e mudase para Bruxelas. Ali escreve, entre outros, A Ideologia Alemã. Não é por acaso, também, que justamente nesta época se aprofundava seu contato com as lutas proletárias e seu estudo sobre a filosofia socialista e comunista francesa. Em 1846 Marx e Engels organizam, em Bruxelas, o primeiro Comitê de Correspondência da Liga dos Justos, e em 1847 filiam-se diretamente a esta Liga, sendo em seguida nomeada de Liga dos Comunistas. Neste ano, também, realiza-se o primeiro congresso da associação em Londres, donde se encomenda da parte de Marx e Engels a composição do Manifesto do Partido Comunista, que seria entregue em 1848. Assim, é nesse ínterim de três anos (1845 a 1848) de estudos do conceito de sociedade civil, do socialismo e comunismo francês, e de sua aproximação definitiva da luta proletária, que Marx teria elaborado novas teses, contrariando, em seu núcleo, aquelas dos

110 Negatividade e inversão da Dialética Especulativa de Hegel... 
Manuscritos de 1844. Não é por acaso que, após os estudos das correntes francesas, Marx afirma no Manifesto do Partido Comunista:

Nas condições alemãs, a literatura francesa perdeu todo significado prático imediato e assumiu um caráter puramente literário. (...) Do mesmo modo, para os filósofos alemães do século XVIII, as reivindicações da primeira revolução francesa não foram mais do que reivindicações da "razão prática". (...) Escreveram seus absurdos filosóficos por detrás do original francês. Por exemplo, por detrás da crítica francesa das relações monetárias escreveram "alienação da essência humana"; por detrás da crítica francesa do Estado burguês escreveram "superação do domínio do universal abstrato"; e assim por diante (MARX, 2005, p. 91-92).

$\mathrm{O}$ "acerto de contas" de Marx em relação às correntes idealistas alemãs percorreu as correntes francesas. Teria sido nestas investigações que ele vislumbrou novos horizontes, onde vira na luta proletária a antítese que levaria às suas teses de $O$ Capital, mas que ainda se apresentavam em rompimento e elaboração. Na continuidade do texto, o autor deixa mais claro suas posições em relação ao pensamento alemão:

Assim, aliteraturasocialista-comunistafrancesafoi completamente castrada. E como nas mãos dos alemães ela tinha deixado de ser a expressão da luta de uma classe contra outra, o alemão convenceu-se de ter superado a "unilateralidade francesa" e de ter defendido não verdadeiras necessidades, mas a necessidade verdadeira, não os interesses do proletariado, mas os interesses do ser humano, do homem em geral, do homem que não pertence 
a classe nenhuma, que não pertence a nenhuma realidade, e que apenas existe no céu nebuloso da fantasia filosófica (Ibid., p. 92).

Não seria, neste sentido, o próprio Marx das teses de 1844 que concebia "os interesses do ser humano", teorizando sobre "o homem em geral", e "que não pertence a classe nenhuma"? A tentativa de construir um materialismo que se opusesse às abstrações hegelianas parecem ter levado Marx a uma encruzilhada entre os anos de 1845 e 1848.

\section{A destruição do elemento especulativo e a problemática do negativo - a arquitetônica de $O$ Capital}

Na inviabilidade de adentrar outros escritos de Marx, passemos aos anos de 1857 a 1867, anos de elaboração de O Capital. É de se ressaltar, entretanto, que até este período intensificou-se a atividade de Marx na luta operária e o aprofundamento nos estudos de economia.

É de grande conhecimento a intenção do materialismo histórico de inverter a dialética hegeliana, de fazê-la deixar de caminhar com a cabeça para caminhar com os pés. É neste sentido que Marx afirma, no Prefácio da segunda edição de O Capital: “Em Hegel, a dialética está de cabeça para baixo. É necessário pô-la de cabeça para cima, a fim de descobrir a substância racional dentro do invólucro místico" (MARX, 1998, p. 29). Assim, vemos que, se Marx abandonou algumas perspectivas ligadas ao ser genérico, não abandonou, de maneira alguma, os problemas que a dialética hegeliana lhe impunha.

Porém, se já nos Manuscritos de 1844 Marx elaborava a crítica do caráter abstrato de Hegel, o que restaria neste momento para se inverter? Vejamos.

Marx teria, ao nosso ver, levado cada vez mais longe a tese dos "homens históricos reais" presente em A Ideologia Alemã, a tal ponto que culminaria, no Manifesto, a compreender que a igualdade entre os homens se dá somente na medida em que as relações sociais permitem.

112 Negatividade e inversão da Dialética Especulativa de Hegel... 
É preciso, portanto, reinterpretar aquela inversão da dialética hegeliana operada por Marx. Com a nova elaboração, dá-se um sentido novo ao termo alemão umstülpen, que pode servir tanto como inverter quanto virar ao avesso. Como aponta H. Fulda, citado por Grespan (2002, p. 27), o termo umstülpen pode significar virar para baixo um vasilhame, derramando o que contém nele, virando de cabeça para baixo, como se interpreta correntemente. Porém, pode-se interpretá-lo diante de sua derivação do substantivo Stulpe, que designa a manga de uma camisa ou a boca de uma calça, o verbo umstülpen significando, neste contexto, arregaçar a manga da camiseta, a boca da calça, ou mesmo a boca de uma bota ou uma luva. No caso de Marx, ele veria o método dialético de Hegel como um método já invertido, mistificado, sendo necessário invertê-lo novamente, desvirá-lo. Como aponta Grespan, não se trata, por isso, somente de passar de um princípio idealista para um princípio materialista, pois, nesta ótica, "o que se 'inverte' é apenas a ordem do real sobre o qual opera a dialética" (GRESPAN, 2002, p. 29), como se faz com uma ampulheta para se reiniciar a contagem do tempo. É necessário, se não quisermos ser levados a concluir que Marx foi ingênuo quanto à relação de forma e conteúdo, virar ao avesso a dialética hegeliana, salvaguardando o núcleo, ou o caroço (Kern) racional de seu envoltório (Hülle) místico: é necessário que a unidade especulativa, que enreda a contradição e a resolve harmoniosamente, dê lugar à contradição, e aí sim tratarmos Marx como autor de uma dialética de fato revolucionária ${ }^{5}$ - o que Marx vinha buscando desde sua juventude. Deste modo, o contraditório deixará de ser um momento na elaboração da unidade especulativa da ideia lógica, para constituir-se, de fato, enquanto fundamento que põe e, por isso, enreda a unidade lógica almejada do capital. Não mais se busca uma unidade

${ }^{5}$ Uma vez que nosso objetivo é abordar algumas questões que avaliamos como pertinentes somente em relação ao desenvolvimento teórico de Marx, não trataremos aqui em pormenores as implicações em $O$ Capital. Para uma investigação mais detalhada da relação entre forma e conteúdo em $O$ Capital diante desta interpretação do termo umstülpen, ver o genial artigo de Jorge Grespan citado na bibliografia.

caderno cemarx, $\mathrm{n}^{\mathrm{0}} 7-2014$ 
dialética conciliadora, como acarretava o método hegeliano. O que se busca agora é inverter as determinações da reflexão de Hegel, a diferença e a identidade. Se para o idealismo hegeliano a identidade é o termo maior e total, preponderando sobre a diferença e resolvendo-a, em Marx, inversamente, a diferença não será mais redutível à uma identidade conciliadora e total.

Ou seja, retomando a metáfora da luva desvirada do avesso: em Hegel a diferença estaria do lado de fora e a identidade no de dentro; enquanto em Marx, ao contrário, a identidade é que aparece no lado de fora, determinada por uma diferença no lado de dentro (GRESPAN, 2002, p. 31).

No que diz respeito ao nosso presente objetivo, Marx teria visto que, ainda mais fundo do que a unidade e idealidade do ser genérico, há uma contradição que fundamenta todas as relações sociais, ou seja, toda a estrutura do real, acarretando em consequências drásticas na estrutura lógica de sua dialética materialista enquanto método. As reflexões presentes em A Ideologia Alemã só se completariam sob esta nova formulação.

Em O Capital a dialética é compreendida como "a maneira de proceder do pensamento" capaz de espelhar no pensamento a vida da matéria, e não como uma construção de uma unidade a priori de caráter profundamente ontológico. Não bastava, portanto, profanar as categorias de Hegel, como os hegelianos de esquerda, invertendo superficialmente a dialética. Era acima de tudo necessário dissolver a unidade ontológica do real, encontrar ali o negativo no interior de sua identidade - daí o sentido de virar ao avesso. Estava Marx, deste modo, em posse dos instrumentos que abririam as portas para encontrar no conceito de negatividade a superação definitiva da dialética de Hegel.

Marx, por isso, não incorre mais em uma unidade última que se esconde por detrás das contradições como formas de aparecimento desta unidade. Ao contrário, mostra-se que há uma aparência de

114 Negatividade e inversão da Dialética Especulativa de Hegel... 
unidade escondendo por detrás das contradições de um sistema social dominante. Como afirma Müller:

Não basta inverter, uma segunda vez, aquilo que a especulação já inverteu, com a intenção de fazer a dialética hegeliana andar com os próprios pés, para que ela revele um potencial de racionalidade que a projete além de seus limites idealistas. É preciso, além de invertê-la, virá-la ao avesso, como exige a outra significação presente na palavra alemã "umstülpen", mostrando que as contradições presentes nos fenômenos não são a aparência de uma unidade essencial, mas a essência verdadeira de uma 'objetividade alienada' (e não da 'objetividade enquanto tal'), e que a sua resolução especulativa na unidade do conceito é que representa o lado aparente, mistificador, de uma realidade contraditória (MÜLLER, 1982, p. 26).

Se nos Manuscritos de 1844 Marx não representava o real em conceitos do mero pensamento, por outro lado, não conseguiu quebrar com esta representação de uma unidade lógica e, em última instância, ontológica. Agora, elaborando em "O Capital” aquelas inquietações que surgiram entre os anos de 1845 e 1848, Marx constrói uma arquitetônica que dissolve a aparência de uma unidade do real para mostrar uma negatividade que fundamenta toda realidade social.

Em O Capital Marx parte da aparência da unidade da mercadoria e mostra que nela se esconde uma contradição entre valor-de-uso e valor-de-troca. Ademais, demonstra que a categoria dinheiro, aparente unidade monetária, carrega em seu núcleo o desenvolvimento da contradição interna da mercadoria externalizada na relação de troca. Neste ínterim, mostra como na circulação simples os agentes sociais são tomados como iguais entre si, e como só se trocam valores equivalentes, etc., leis estas que logo se apresentam como sendo seus opostos. É no final do capítulo IV - "Como o dinheiro se transforma em capital" que 
Marx sintetiza as desmistificações daquelas unidades aparentes que se promovia na esfera da circulação: liberdade, igualdade, propriedade e Bentham. Porém, adverte Marx:

Ao deixar a esfera da circulação simples ou da troca de mercadorias (...) parece-nos que algo se transforma na fisionomia dos personagens do nosso drama. $\mathrm{O}$ antigo dono do dinheiro agora à frente, como capitalista; segue-o o proprietário da força de trabalho, como seu trabalhador. O primeiro, com um ar importante, sorriso velhaco e ávido de negócios; o segundo, tímido, contrafeito, como alguém que vendeu sua própria pele e apenas espera ser esfolado (MARX, 1998, p. 206).

Adentrando nas contradições do real, demonstra que a maisvalia consiste numa região negativa entre o processo de circulação e o processo de produção. As contradições vão se ampliando e se aprofundando, com a mais-valia absoluta e relativa, o capital constante e variável, até o ponto culminante no qual se atinge a contradição fundamental, aquela da luta de classes. O conjunto das relações sociais, o real, constituir-se-ia em uma região antitética produzida pela luta de classes. Se, porém, por um lado, Marx busca elaborar em O Capital o conceito de capital como aquele que englobaria em si todas as relações sociais de uma determinada época, levando, assim, a uma unidade do capital consigo mesmo, por outro lado, demonstra que a pretensão de dominação total do capital falha, destituindo sua unidade consigo mesmo.

É desta maneira que, ao nosso ver, o conceito de negatividade consiste em um dos pontos centrais para a discussão do verdadeiro acerto de contas com a dialética de Hegel. É nesse sentido que vemos, no desenvolvimento teórico de Marx, sua incessante combatividade, que ele encontrou no encontro do negativo no método dialético:

116 Negatividade e inversão da Dialética Especulativa de Hegel... 
A dialética mistificada tornou-se moda na Alemanha, porque parecia sublimar a situação existente. Mas, na sua forma racional, causa escândalo e horror à burguesia e aos porta-vozes de sua doutrina, porque sua concepção do existente, afirmando-o, encerra, ao mesmo tempo, o reconhecimento da negação e da necessária destruição dele; porque apreende, de acordo com seu caráter transitório, as formas em que se configura o devir; porque, enfim, por nada se deixa impor; e é, na sua essência, crítica e revolucionária (Ibid., p. 29).

Enfim, concluímos que sua obra se desenvolve não com uma tese única e sem mudanças, mas com uma problemática única, aquela de como expressar teórica e metodologicamente a própria combatividade histórica de classes rumo à destruição do sistema capitalista. Essa expressão teórica só poderia surgir, porém, com a resolução da forma da dialética, com a precisa determinação da negatividade. Entretanto, Marx vira que esta crítica e revolução só poderiam ser expressas, teórica e metodologicamente, com a dialética. Portanto, se há um desenvolvimento teórico na obra de Marx, este sempre se consistiu na pergunta que parece tê-lo assombrado a vida toda, feita ainda nos Manuscritos de 1844; uma pergunta, como ele próprio diz, "aparentemente formal, mas efetivamente essencial", a saber: "o que fazer diante da dialética hegeliana?" (MARX, 2004, p. 115).

\section{Bibliografia}

FULDA, H. F. "These zur Dialektik als Darstellungsmethode (im 'Kapital' von Marx)”, In: Hegel Jahrbuch, Köln, Pahl-Rugenstein, Verlag, 1974.

GRESPAN, Jorge. "A dialética do avesso". Crítica Marxista, São Paulo, n. 14, 2002. 
HEGEL, Georg W. F. Enciclopédia das ciências filosóficas, I - A Ciência da Lógica. Trad. Paulo Meneses. São Paulo: Loyola, 1995.

. Fenomenologia do Espírito. Trad. Paulo Meneses. Petrópolis, RJ: Vozes; Bragança Paulista: Editora Universitária São Francisco, 2005.

MARX, Karl. Manuscritos Econômico-Filosóficos. Trad. Jesus Ranieri. São Paulo: Boitempo, 2004.

- Para a crítica da economia política. Trad. José Arthur Giannotti e Edgar Malagodi. São Paulo: Abril Cultural, 1978. (Coleção Os Pensadores).

- O Capital. Trad. Reginaldo Sant'Anna. Rio de Janeiro: Civilização Brasileira, 1998.

MARX, Karl; ENGEL, Friedrich. A Ideologia Alemã. Trad. José Carlos Bruni e Marco Aurélio Nogueira. São Paulo: Hucitec, 1987.

. Manifesto do Partido Comunista. Trad. Marco Aurélio Nogueira e Leandro Konder. Bragança Paulista: Ed. Universitária São Francisco, 2005.

MÜLLER, Marcos. “Exposição e Método Dialético em 'O Capital”'. Boletim Seaf, Minas Gerais, n. 02, 1982. 